06.1

\title{
Новые гетерогенные наноструктурные катализаторы на основе наночастиц переходных металлов и гексагонального нитрида бора
}

\author{
(ㄷ А.С. Конопацкий ${ }^{1}$, К.Л. Фаерштейн ${ }^{2}$, И.Н. Волков ${ }^{1}$, Д.В. Лейбо ${ }^{1}$, В.В. Калинина ${ }^{1}$, Д.В. Гольберг ${ }^{2}$, \\ Д.В. Штанский ${ }^{1}$ \\ ${ }^{1}$ Национальный исследовательский технологический университет „МИСиС“, Москва, Россия \\ ${ }^{2}$ Технологический университет Квинсленда, Брисбен, Австралия \\ E-mail: konopatskiy@misis.ru
}

Поступило в Редакцию 16 апреля 2021 r.

В окончательной редакции 1 мая 2021 г.

Принято к публикации 7 мая 2021г.

Изучены структура и каталитическая активность новых гетероструктурных наноматериалов $\mathrm{FePt} / h-\mathrm{BN}$ в реакции окисления монооксида углерода. Структура и состав поверхности анализировались методами просвечивающей электронной микроскопии, рентгеновской фотоэлектронной спектроскопии и рентгенофазового анализа. Показано, что разработанные материалы проявляют выраженную каталитическую активность и позволяют достичь полной конверсии СО при температуре $250^{\circ} \mathrm{C}$. В процессе термической активации происходит упорядочение структуры наночастиц FePt.

Ключевые слова: наноматериалы, гетерогенный катализ, гексагональный нитрид бора, термообработка.

DOI: 10.21883/PJTF.2021.16.51320.18832

В последнее время большое внимание привлекают гетерогенные катализаторы на основе гексагонального нитрида бора $(h$-BN $)$, выступающего в роли подложки для каталитически активных частиц [1]. Известно, что наночастицы серебра, палладия, платины и др. проявляют выраженные каталитические свойства в ряде промышленно значимых реакций [2]. Однако все большее развитие получают биметаллические каталитические системы [3], управление свойствами которых возможно за счет контроля их химического состава [4]. Апробирование новых каталитических наносистем удобно проводить на примере модельных химических реакций, имеющих тем не менее важное прикладное значение. К таким реакциям относят процесс окисления монооксида углерода. В рамках настоящей работы были синтезированы новые гетерогенные катализаторы $\mathrm{FePt} / \mathrm{BN}$, изучены их структура и каталитическая активность в реакции окисления CO. Ocобое внимание уделено изучению структуры и химического состояния поверхности материала после термической активации, являющейся обязательным этапом предварительной обработки катализатора.

Гетерогенные катализаторы FePt/BN были получены в ходе полиольного процесса. Для этого $200 \mathrm{mg}$ порошка $h$-BN диспергировали в $100 \mathrm{ml}$ этиленгликоля и перемешивали на магнитной мешалке в процессе ультразвуковой обработки в течение $5 \mathrm{~min}$. По достижении однородной суспензии среду синтеза перемещали на лабораторную плитку и нагревали до $180^{\circ} \mathrm{C}$. Для предотвращения агломерации наночастиц $h$-BN среду синтеза подвергали ультразвуковой обработке (мощность 15\%) при помощи погружного сонотрода. При достижении указанной температуры в среду синтеза добавляли $\mathrm{H}_{2} \mathrm{PtCl}_{4}$ и $\mathrm{FeCl}_{3} \cdot 3 \mathrm{H}_{2} \mathrm{O}$ в молярном соотношении 1:40. Затем добав- ляли $3.6 \mathrm{~g} \mathrm{NaOH}$ и выдерживали в течение $3 \mathrm{~min}$, после чего оставляли среду синтеза остывать под вытяжкой. По достижении среды синтеза комнатной температуры проводили ее центрифугирование $(8500 \mathrm{rpm})$ в течение $30 \mathrm{~min}$ и последующую промывку в дистиллированной воде. Осадок после просушки собирали и использовали для дальнейшего анализа.

Изучение каталитической активности проводилось для реакции окисления СО в проточном кварцевом реакторе. В качестве образца для каждого испытания было использовано $25 \mathrm{mg}$ катализатора, смешанного с кварцевыми гранулами. Измерение активности проводилось при газовом потоке с составом $5.6 \% \mathrm{CO}, 11.1 \% \mathrm{O}_{2}$, $83.3 \% \mathrm{He}\left(43200 \mathrm{ml} \cdot \mathrm{g}_{\text {cat }}^{-1} \cdot \mathrm{h}^{-1}\right)$ и величиной $36 \mathrm{ml} / \mathrm{min}$ при атмосферном давлении. Продукты реакции изучались на масс-спектрометре (ThermoStar). Перед каталитическими испытаниями проводился отжиг материала при температуре $500^{\circ} \mathrm{C}$ в течение $8 \mathrm{~h}$ в атмосфере водорода, что является распространенной схемой термической активации катализатора на основе металлических частиц. По окончании отжига печи давали остыть до комнатной температуры, после чего проводились каталитические испытания. Конверсия монооксида углерода определялась как

$$
X=1-\frac{Q_{\mathrm{CO}}^{f}}{Q_{\mathrm{CO}}^{s}},
$$

где $Q_{\mathrm{CO}}^{s}-$ исходный поток $\mathrm{CO}$, а $Q_{\mathrm{CO}}^{f}-$ поток $\mathrm{CO}$ на выходе из реактора.

Ввиду того что активация может привести к заметным структурным изменениям материала, анализ структуры осуществлялся для двух состояний: до активации, т.е. сразу после синтеза, и после активации, т.е. в том 


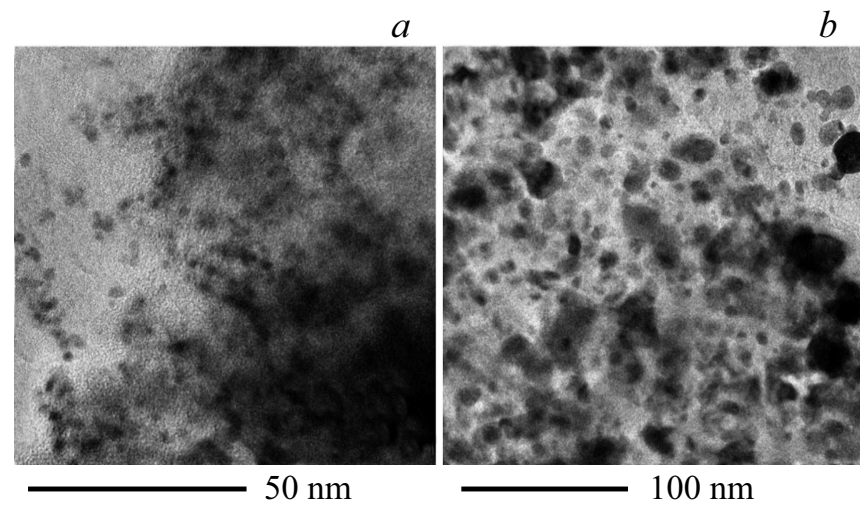

Рис. 1. Электронно-микроскопические изображения $\mathrm{FePt} / \mathrm{BN}$ до активации $(a)$ и после активации $(b)$.

состоянии, в котором катализатор принимает участие в каталитическом процессе. Для изучения структуры полученных материалов использовался метод просвечивающей электронной микроскопии (ПЭМ) (ЈЕМ 2100). Химический и фазовый состав, а также структура поверхности материала изучались методами рентгеновской фотоэлектронной спектроскопии (РФС) (AXIS Supra surface analysis instrument) и рентгенофазового анализа (РФА) (ДРОН-3).

На рис. 1 представлены ПЭМ-изображения материала до и после активации. После синтеза поверхность частиц $h$-BN равномерно покрыта металлическими наночастицами со средним размером $3.4 \mathrm{~nm}$, при этом размер наиболее крупных частиц достигает $5 \mathrm{~nm}$ (рис. 1,a). В результате термической активации происходит агломерация металлических частиц, что приводит к росту их среднего размера до $8.6 \mathrm{~nm}$, наиболее крупные частицы достигают в диаметре $20 \mathrm{~nm}$ (рис. 1,b). Также наблюдается изменение морфологии наночастиц: все больше частиц приобретает неправильную форму в результате агломерации исходных наночастиц. Таким образом, оба образца представляют собой порошковый материал, состоящий из гетерогенных наночастиц $\mathrm{FePt} / \mathrm{BN}$, в которых биметаллические частицы расположены на поверхности $h$-BN.

На рис. 2 приведены результаты изучения особенностей поверхности и фазового состава полученных материалов методами РФС и РФА.

На спектрах РФС Fe $2 p$ и $\mathrm{Pt} 4 d$ образцов $\mathrm{FePt} / \mathrm{BN}$ непосредственно после синтеза ярко выраженных пиков не наблюдается. Однако после активации сигналы от железа и платины становятся хорошо различимыми. Наблюдаются дублеты в областях 710-730 eV (Fe 2p) и 310-340 eV (Pt 4d). Увеличение интенсивности пиков может быть связано с удалением с поверхности частиц остаточных полимерных соединений и побочных продуктов синтеза в ходе термической активации. Полученный результат подчеркивает важность этапа активации катализатора, так как его свойства в химических реакциях напрямую зависят от состава и структуры поверхности.
Содержание железа и платины, рассчитанное по результатам РФС-анализа образцов $\mathrm{FePt} / \mathrm{BN}$ после отжига, составило соответственно 5.2 и 2.8 at.\%. Разложение сигнала $\mathrm{Fe} 2 p_{3 / 2}$ на компоненты с применением функции Гаусса позволяет установить присутствие железа со следующими степенями окисления на спектре образца после активации: $\mathrm{Fe}^{3+}(711.0 \mathrm{eV}), \mathrm{Fe}^{2+}(712.6 \mathrm{eV})$. Это указывает на то, что на поверхности наночастиц $\mathrm{FePt}$ присутствует некоторое количество кислорода, связанного с ионами железа. Величина энергии связи каждого из пиков Pt $4 d_{5 / 2}(315.3 \mathrm{eV})$ и $\mathrm{Pt} 4 d_{3 / 2} \quad(332.8 \mathrm{eV})$, а также возможность их аппроксимации с применением одной компоненты указывают на металлическое состояние платины. По сравнению с известными литературными данными [5] наблюдается небольшое смещение сигнала $\mathrm{Pt} 4 d$ в сторону больших энергий связи. Такой сдвиг часто объясняется в рамках модели переноса заряда [6]. Данная модель хорошо отражает изменения в РФС-спектре в случае образования ионной или ковалентной связи. Однако в случае металлической связи, как в рассматриваемой двухкомпонентной системе FePt, сдвиг может быть вызван процессом упорядочения в структуре FePt, протекающим в ходе термической обработки, и сопутствующими изменениями в электронной структуре сплава.

По результатам РФА, представленным на рис. 2,c, видно, что после синтеза основными компонентами материала являются $h$-BN и наночастицы FePt. Значительное уширение рентгеновского рефлекса FePt (111) указывает на малый размер частиц. После отжига ширина наиболее интенсивного пика FePt (111) уменьшается, что связано с укрупнением наночастиц FePt в ходе активации. Средний размер кристаллитов, рассчитанный по формуле Дебая-Шеррера, составил $2.2 \mathrm{~nm}$ для образца до активации и $6.5 \mathrm{~nm}$ для образца после активации, что хорошо согласуется с результатами ПЭМ. Наблюдается смещение пиков FePt (111) и (200) в сторону больших углов 20, а также появляется новый пик $\mathrm{FePt}$ (110). Эти изменения характерны для процесса упорядочения в FePt эквиатомного состава со структурой А1 и формирования „сверхструктуры“ $L 1_{0}$-FePt [7], что согласуется с результатами РФС-анализа. Положительное влияние упорядочения структуры FePt на каталитические свойства (например, в реакции восстановления кислорода) отмечалось ранее [7].

На рис. 3 представлены результаты изучения каталитической активности гетерогенного наноматериала $\mathrm{FePt} / \mathrm{BN}$. C целью сравнения использовался образец достаточно распространенной в гетерогенном катализе системы $\mathrm{Au} / \mathrm{Al}_{2} \mathrm{O}_{3}$, также полученный полиольным методом. Размер частиц $\mathrm{Al}_{2} \mathrm{O}_{3}$ составлял около $100 \mathrm{~nm}$, расчетное содержание $\mathrm{Au}-10$ mass $\%$.

Видно, что материал проявил выраженную каталитическую активность в рассматриваемой реакции. Полная конверсия монооксида углерода была достигнута при температуре $250^{\circ} \mathrm{C}$. Наиболее высокая скорость роста 

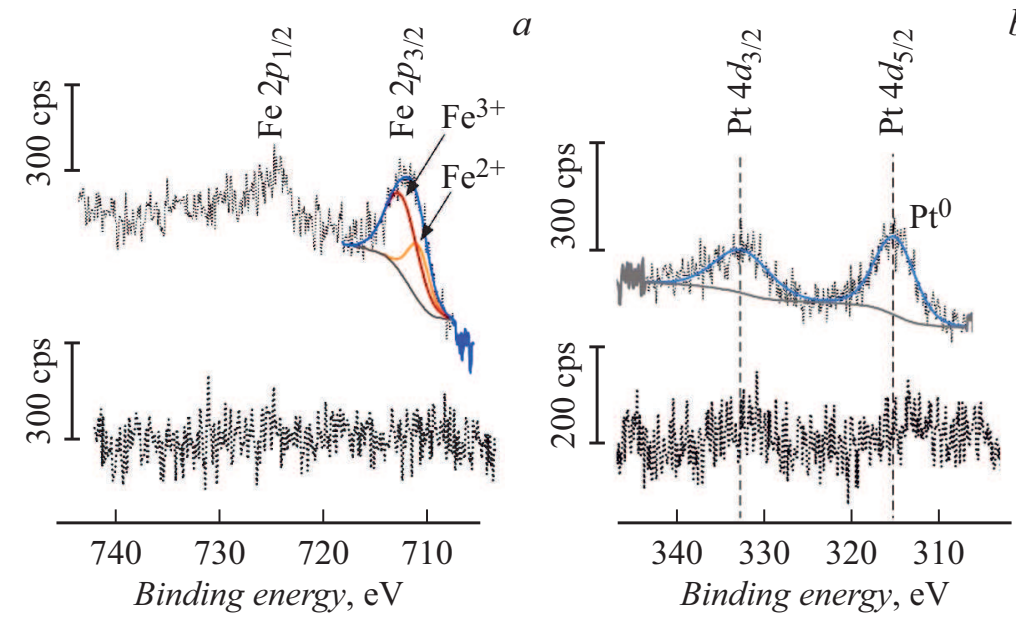

$b$

$c$

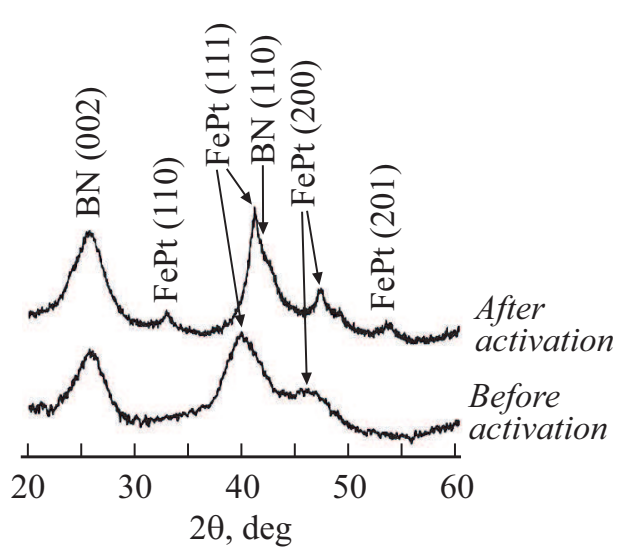

Рис. 2. РФС- $(a, b)$ и РФА-спектры (c) FePt/BN до активации (нижние спектры) и после активации (верхние спектры).

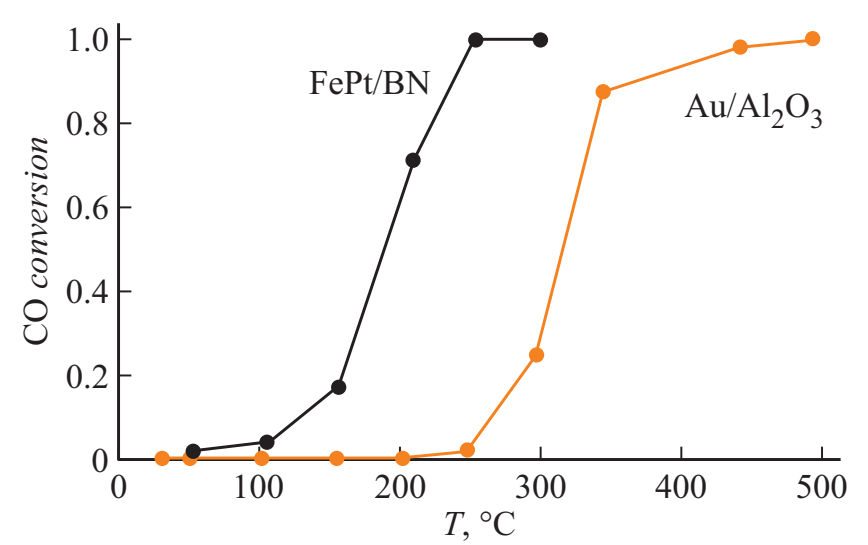

Рис. 3. Каталитическая активность $\mathrm{FePt} / \mathrm{BN}$ и $\mathrm{Au} / \mathrm{Al}_{2} \mathrm{O}_{3}$ в реакции окисления СО.

конверсии (от 20 до 80\%) находится в интервале температур от 150 до $250^{\circ} \mathrm{C}$. В то же время образец сравнения показал гораздо более высокую (около $440^{\circ} \mathrm{C}$ ) температуру полной конверсии. Одним из этапов каталитического процесса конверсии СО являются адсорбция и диссоциация молекулярного кислорода на активных центрах катализатора. Высокая термическая стабильность и энергетический барьер диссоциации молекулярного кислорода затрудняют реакцию окисления СО. Однако было показано [8], что биметаллические системы способствуют снижению этого энергетического барьера и активации кислорода за счет повышенной энергии адсорбции, что может являться причиной повышения конверсии СО.

Таким образом результаты каталитических испытаний показали, что система $\mathrm{FePt} / \mathrm{BN}$ представляет собой новый перспективный катализатор для реакции окисления монооксида углерода. Результаты РФА и РФС позволили установить, что этап термической активации вызывает не только увеличение среднего размера каталитически активных наночастиц, но также приводит к процессам упорядочения их структуры, что может оказывать влияние на их функциональные свойства.

\section{Финансирование работы}

Работа выполнена при финансовой поддержке Российского научного фонда (соглашение № 20-79-10286).

\section{Конфликт интересов}

Авторы заявляют, что у них нет конфликта интересов.

\section{Список литературы}

[1] Y. Chen, J. Cai, P. Li, G. Zhao, G. Wang, Y. Jiang, J. Chen, S.X. Dou, H. Pan, W. Sun, Nano Lett., 20, 6807 (2020). DOI: 0.1021/acs.nanolett.0c02782

[2] L. Liu, A. Corma, Chem. Rev., 118, 4981 (2018). DOI: $10.1021 /$ acs.chemrev.7b00776

[3] A. Verlee, T. Heugebaert, T. Van Der Meer, P. Kerchev, K. Van Hecke, F. Van Breusegem, C.V. Stevens, ACS Catal., 9, 7862 (2019). DOI: 10.1021/acscatal.9b02275

[4] A.M. Kovalskii, A.T. Matveev, Z.I. Popov, I.N. Volkov, E.V. Sukhanova, A.A. Lytkina, A.B. Yaroslavtsev, A.S. Konopatsky, D.V. Leybo, A.V. Bondarev, I.V. Shchetinin, K.L. Firestein, D.V. Shtansky, D.V. Golberg, Chem. Eng. J., 395, 125109 (2020). DOI: 10.1016/j.cej.2020.125109

[5] W.D. Schneider, C. Laubschat, Phys. Rev. B, 23, 997 (1981). DOI: 10.1103/PhysRevB.23.997

[6] L. Chen, A. Yelon, J. Phys. Chem. C, 116, 6902 (2012). DOI: $10.1021 / \mathrm{jp} 301372 \mathrm{j}$

[7] R.Sandström, E. Gracia-Espino, A. Annamalai, P.O.Å. Persson, I. Persson, J. Ekspong, H.R. Barzegar, T. Wågberg, Energy Mater., 3, 9785 (2020). DOI: 10.1021/acsaem.0c01368

[8] M.A. Dar, S. Krishnamurty, ACS Omega, 4, 12687 (2019). DOI: 10.1021/acsomega.9b01581 